\title{
Insights into factors affecting the combined bicycle-transit mode
}

\author{
Joeri F. P. van Mil ${ }^{1} \cdot$ Tessa S. Leferink $^{2} \cdot$ Jan Anne Annema ${ }^{3} \cdot$ Niels van Oort $^{3}$ (ID
}

Accepted: 11 June 2020 / Published online: 5 July 2020

(c) The Author(s) 2020

\begin{abstract}
This paper considers an increasingly popular, sustainable multimodality: the combination of bicycle and transit. The flexibility of the bicycle combined with the speed and comfort of good transit can be a highly competitive alternative to the car. This study shows that many factors influence the uptake and attractiveness of the bicycle-transit combination. An in-depth literature review resulted in over thirty unique factors: six transit-related factors, twenty-first-last mile factors and fifteen contextrelated factors. All these factors might influence the demand for this 'new' mode positively or negatively. An exploratory choice modelling study showed the weights of some factors that Dutch bicycle-train users consider when choosing to cycle to a railway station. The weights showed that people are especially willing to cycle to a station with longer bicycle time (or bicycle parking time) when by doing so they can avoid a transfer in their train trip thereafter. The willingness to pay found were $€ 0.11$ for $1 \mathrm{~min}$ less bicycle time, $€ 0.08$ for a minute less train time, $€ 0.11$ for a minute of less time to park and $€ 0.60$ per avoided transfer. These kinds of insights give the bicycle and transit sector valuable information to be used in modelling multimodality and cost-benefit analyses, thereby supporting improved decision making and integrated design of bicycle and transit networks.
\end{abstract}

Keywords Transit $\cdot$ Cycling $\cdot$ Behaviour

Niels van Oort

N.vanOort@tudelft.nl

1 AT Osborne, Baarn, The Netherlands

2 Witteveen+Bos, Deventer, The Netherlands

3 Delft University of Technology, Delft, The Netherlands 


\section{Introduction}

This paper considers an increasingly popular, sustainable multimodality: the combination of bicycle and transit. The flexibility of the bicycle combined with the speed and comfort of good transit can be a highly competitive alternative to the car. To decrease congestion and levels of air pollution, and improve their citizens' health, governments might encourage the bicycle-transit mode. Particularly when combined with the train, metro, bus rapid transit (BRT) and light rail transit (LRT), bicycle-transit can be very successful (Shelat et al. 2018). When bicycle and transit networks and systems are well integrated, people will cycle further to reach stations and stops (Brand et al. 2017; Rijsman et al. 2019). This directly increases the catchment area and accessibility of the transit system. Bicycletransit combines the advantages of speed and accessibility of (particularly higher level) transit with the flexibility and reliability of the bicycle. Recent publications have highlighted the potential of the marginalised and little researched bicycletransit combination (Jonkeren et al. 2019; Kager et al. 2016; KiM 2016b; Scheltema 2012). This paper aims to provide new knowledge on the bicycle-transit combination.

The bicycle-transit trip can be seen as a chain of different links and nodes, connecting a point of origin and point of destination. Two types can be distinguished: Bike-and-Ride (BaR) and Bike-on-Board (BoB) (see Fig. 1). This research focuses on Bike-and-Ride (BaR) journeys where travellers park their bicycle at the station or stop and use the bicycle at the first and/or last leg of the journey.

Despite the theoretic advantages, bicycle-transit use is limited in worldwide practice. In the European Union on average four percent of rail users arrive or depart from the train station by bicycle (BiTiBi 2016). But there is an exception: in the Netherlands on average $43 \%$ of the home-bound train journeys start or end with a bicycle ride and this number has been growing (KiM 2017). As general levels of bicycle and transit use are increasing worldwide, the number of bicycletransit rides can be expected to rise too.

This paper is structured in two parts. First, the paper gives an overview of factors affecting bicycle-transit demand. Despite the increasing attention for bicycle-transit
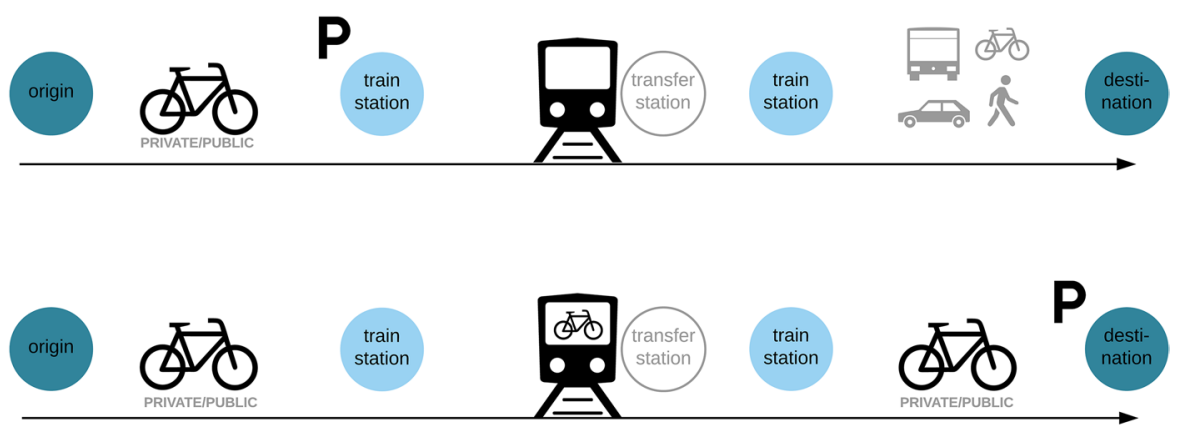

Fig. 1 Top: Bike-and-Ride (BaR); bottom: Bike-on-Board (BoB) trip chains. Visualisation by authors 
in research, a coherent literature overview of these factors is lacking (BachandMarleau et al. 2011). Second, based on this overview, our study aims to give some quantitative insights into the impact of some factors which were found in the literature review influencing the combined bicycle-rail transit. Namely: bicycle time to station, time to park bike, parking costs, train time and transfer (whether there is a transfer within the train trip). This second part is explorative and carried out in the Dutch context. It concerns findings from a stated choice experiment.

\section{Methodology}

The paper includes two main methods: a literature review on factors influencing the bicycle-transit combination and a stated choice experiment. The literature was selected through searches in the database of Google Scholar to not only include scientific papers, but also grey publications on the rather new research topic. A first search was made for combinations of keywords 'bicycle/bike/cycle-transit/ train/transit/public transport' and 'bike/bicycle-and-ride/bike/bicycle-on-board'. Sources were selected after reading the abstract, to only include papers considering 'factors' (also defined as characteristics, key variables, determinants or aspects). The snowballing technique was used in a second search by looking at the reference list of the selected papers. This review includes over fifty publications in the English or Dutch language.

The structuring of the factors and their relationship to bicycle-transit use is the result of an iterative process. By cross-reading the selected papers, an initial list of significantly influential factors (according to the studies reviewed) was made by content analysis. The described factors were summed up per paper. Next, for each factor, the various papers' relevant sections were re-read and summarised. Based on these summaries all factors were assigned a relationship with the amount of bicycle-transit trips. This approach ensured that factors are not only described in text, but also captured in a more general relationship of 'positive' or 'negative' influence on bicycle-rail use (marked by,,+++- or - symbols).

To gain more quantitative insights in passenger preferences, a stated choice experiment was performed and a choice model was constructed. The applied methodology and the results will be described in more detail in Sect. 4.

\section{Factors that influence bicycle-transit demand}

A literature review of over fifty worldwide studies on bicycle-transit yielded nearly forty factors. These influential factors can be grouped along the trip chain: transit, first/last-mile and the larger context. The three groups are composed of the following elements:

- Transit related: System and operating service, journey, and station typology 
- First/last-mile: Regional climate, bicycle journey, and competition other modes

- Context: Culture and attitude, and user characteristics

This paper first describes each group briefly and then presents the related factors in a table. Each factor's relative influence on bicycle-transit demand is captured with a $++/+/-/--$ symbol as a rough indication for a, respectively, (very) positive or (very) negative impact. We have not used a quantitative benchmark but followed the sources' qualitative reflection. These indicators are compared among each other to help provide higher-level guidance on interpreting the factors. Note that correlations between factors will exist. For example, high levels of employment will closely correlate to more commuters on public transport.

For a more detailed description of the literature review we refer to the work of Leferink (2017), and for more understanding of the factors we refer to the original studies in the sources mentioned in the table and text.

It is not surprising that many of the factors for good bicycle-rail integration focus on the transfer area: the transit stop or station. This part of the transit journey is typically valued lowest by travellers (Peek and Van Hagen 2002).

\subsection{Transit-related factors}

The literature has a rich vocabulary related to transit networks, stations or stops, and the transit journey itself. For this research, the following definition of transit is used: a shared transport mode, in a network (connecting stops) that operates on an interval or timetable.

In the introduction, two types of bicycle-transit trip chains were presented. For the transit leg of a journey, bike-and-ride travellers are similar to other transit users after they have parked or collected their bicycle. The differences in transfers and transit may, therefore, mostly be experienced by bike-on-board travellers. This counts particularly for those with a fixed frame bicycle compared to a foldable bike.

Table 1 shows the influential factors related to the transit, their effect and main sources. They are discussed in more detail in the consecutive paragraphs.

\subsubsection{Transit journey}

Typically, the largest part of the bicycle-transit combination is the transit journey, both in terms of time and distance. Still on average $30-50 \%$ of the travel time of bicycle-transit is spent on access and egress according to a Dutch study using active travel diary information (Krygsman et al. 2004), with similar findings in the US (Flamm and Rivasplata 2014). It may be concluded that to compensate for the inconvenience and extra time required to collect, park or board a bicycle, the transit journey must be of significant length. Another study looking at the Dutch railway system stated that for bicycle-rail in particular, the total travel distance must be at least 10-15 km (Van der Loop 1997). For short trips, people may be more inclined to cycle the whole trip or use the car for a more convenient journey. The 


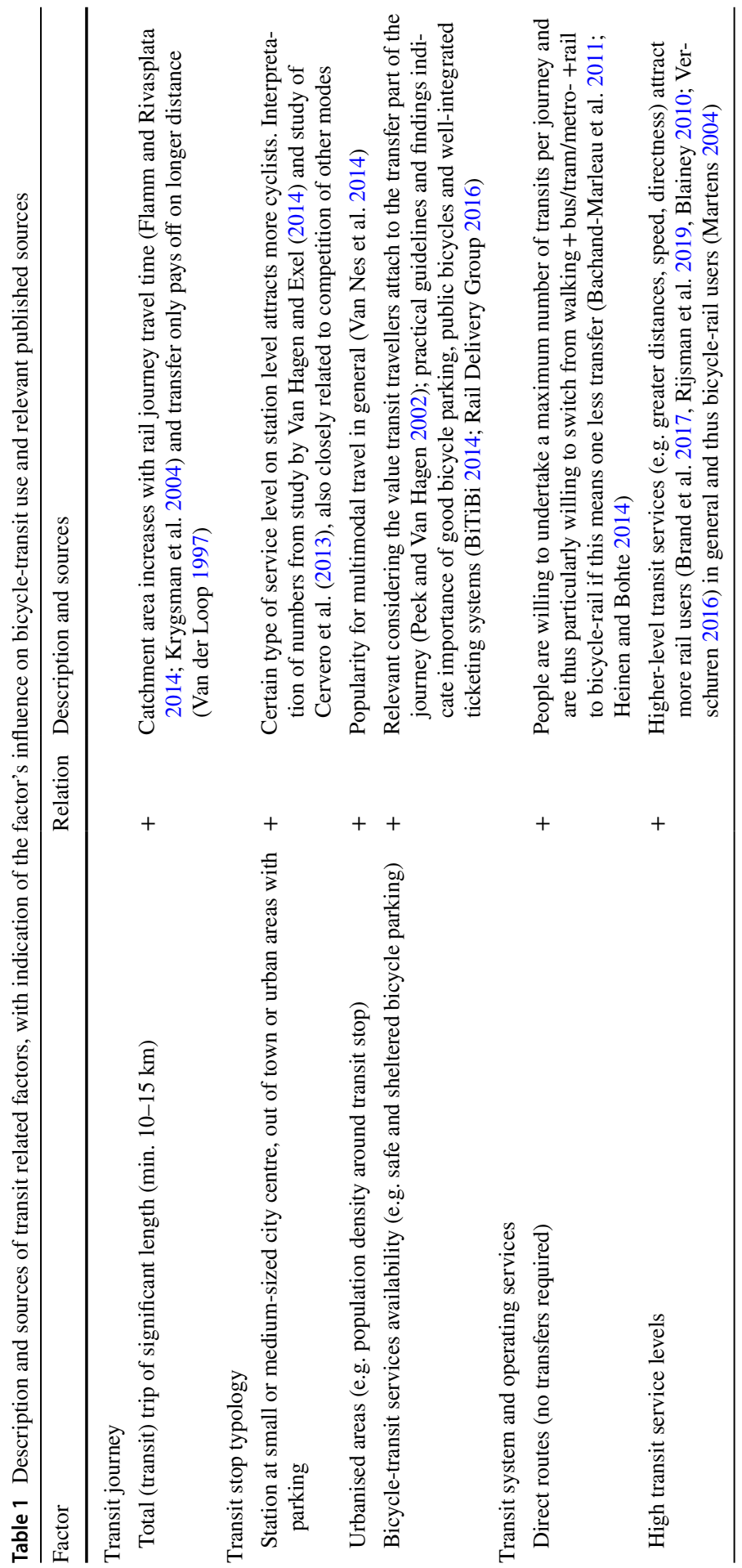


stated choice study described in the second section of this paper looks directly from a traveller's point of view.

\subsubsection{Transit stop typology}

There are many studies on capturing general transit station's attractiveness and accessibility. The relevant factors range from its cleanliness to location in the network, and from the feeling of security to the number of benches according to a Dutch literature study (Groenendijk et al. 2018). Not surprisingly, ensuring a good integration of bicycle-rail at the local station or transit stop level is a requirement. There are various ways to improve bicycle-transit trips directly. Guidelines from an EU knowledge and practice sharing project called BiTiBi mention six vital services: bicycle parking, public bicycles (see examples in Ma et al. 2020), integrated payment systems (e.g. smartcard schemes), collaborations of bicycle-rail organisations, positive communication and safe cycling infrastructure (BiTiBi 2017). These bicycle-transit 'services' are included in this overview to ensure completeness of influential factors, but their effects are not described in more detail here due to large local variation.

The location of a station relates closely to its operating services (see Sect. 3.1.3), but also greatly influence the share of cyclists it attracts and produces. From data presented in a stated travel choice study among railway passengers in the Netherlands it can be noted that particularly semi-urban stations see a relatively high percentage of bicycle-transit users (Van Hagen and Exel 2014). Another Dutch study indicated that the main growth of bicycle-rail use at the turn of the century occurred at the commuter towns (so-called 'voorstadstations') (Van Boggelen and Tijssen 2007).

Similar research was undertaken by Cervero et al. (2013), who divided the 42 light rail stations in the San Francisco Bay Area in five categories based on urban setting and parking provisions. The 'urban with parking' station type was found to have the largest share of access by bicycle (7\% in 2008), where the transit service offered at each station was identical (same frequencies, fares, etcetera). Note that in all these studies the availability of alternative forms of transport play a large role.

\subsubsection{Transit system and operating service}

There are different types of public transport services as well as network typologies. Some systems or stations seem to be more likely to attract cyclists. Both the study by Bachand-Marleau et al. (2011) as well as by Heinen and Bohte (2014) found that if people are able to substitute one leg of their (primarily higher level) transit journey currently undertaken by another form of public transport with the use of a bicycle, they are more keen to switch. As bicycle-transit is already a multimodal trip by definition, any additional transfers are valued more negatively. Thus, stops with more direct services are more attractive. Furthermore, other studies indicate that people will cycle greater distances to higher service level transit stops and stations (Brand et al. 2017; Rijsman et al. 2019; Blainey 2010; Martens 2004; Verschuren 2016). 
Note that these system-wide factors trickle down into the transit station factors of Sect. 3.1.1.

More abstractly, Brand et al. (2017) mention physical and network integration, an integrated ticket system (for paid cycle parking, bike share and the transit journey, such as the Dutch OV-card) and high-quality information system as preconditions of bicycle-transit use. The researchers expect that the quality of Bike-on-Board facilities and availability will also influence the amount of bicycle-transit use. However, no existing literature has been found on this topic particularly. It may be expected that in evaluation reports of train operators such information may be of hand. These literature sources were not part of this research scope.

\subsection{First-/last mile factors}

The bicycle leg of the bicycle-transit journey can make up nearly half of the total trip time as indicated earlier in Sect. 3.1.1. This group of factors contains three subgroups: generic 'regional climate' of a place, quality of the bicycle journey and competition with other modes. Competition applies to both access and egress trips to the train station (competition bicycle), as well as the complete door-to-door journey (competition bicycle-rail). Table 2 shows these factors, their relationship and main sources.

\subsubsection{Regional climate}

There are a number of geographical features that describe bicycle uptake in general and bicycle-rail levels in particular. At a local level these characteristics include the weather, hilliness and city size.

The influence of weather is considered in various studies and even defined as "main external factor" by a study in Taiwan of Cheng and Liu (2012), although user experience can differ. Weather conditions were defined by rain, wind, and temperature. Rainy weather has a "large impact" according to a stated preference survey among rail users in the Netherlands (Molin and Timmermans 2010) and ranked high as well by Van Boggelen and Tijssen (2007). A small but much-quoted empirical research by Bickelbacher in 2001 found a decrease in the share of cyclists to a Munich metro station from 16 to $6 \%$ on rainy days. Seasonal differences indicated a doubling of bicycle-rail use in summertime in the study. The type of users may, however, differ too, as Bachand-Marleau et al. (2011) describe how users cycle more in summer but increase their overall public transport use during the winter-capturing a predictable substitute.

In a survey in the US among bicycle-rail users, 33\% of the participants stated to use bicycle-rail for "avoiding bad weather or riding in the dark" (Flamm and Rivasplata 2014). Note that this was possibly the alternative to cycling the whole trip. Their study also indicated that hilliness may actually increase the use of bicycle-rail compared to bicycle-only trips-arguably trips that otherwise may not have been made at all. 


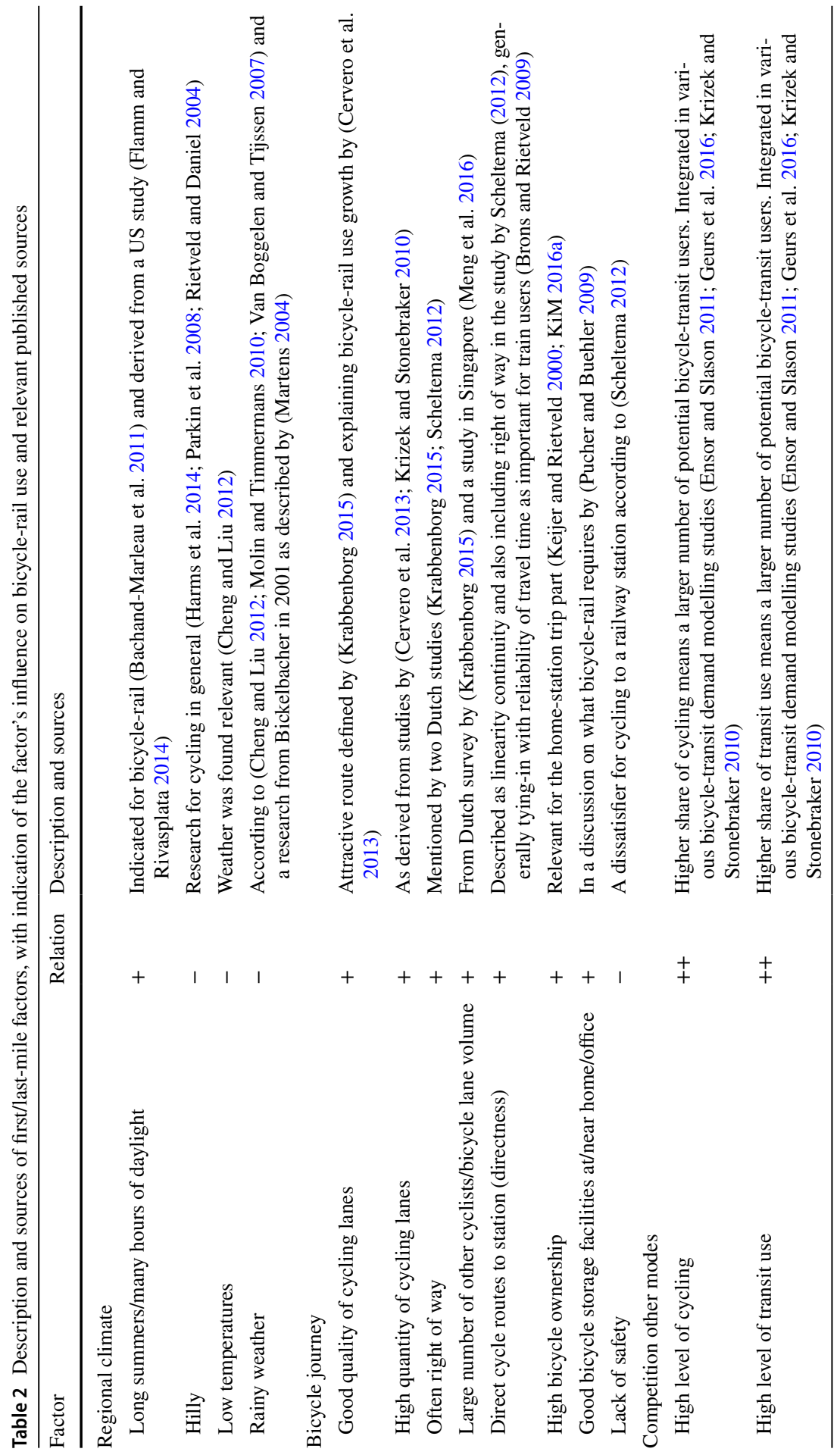




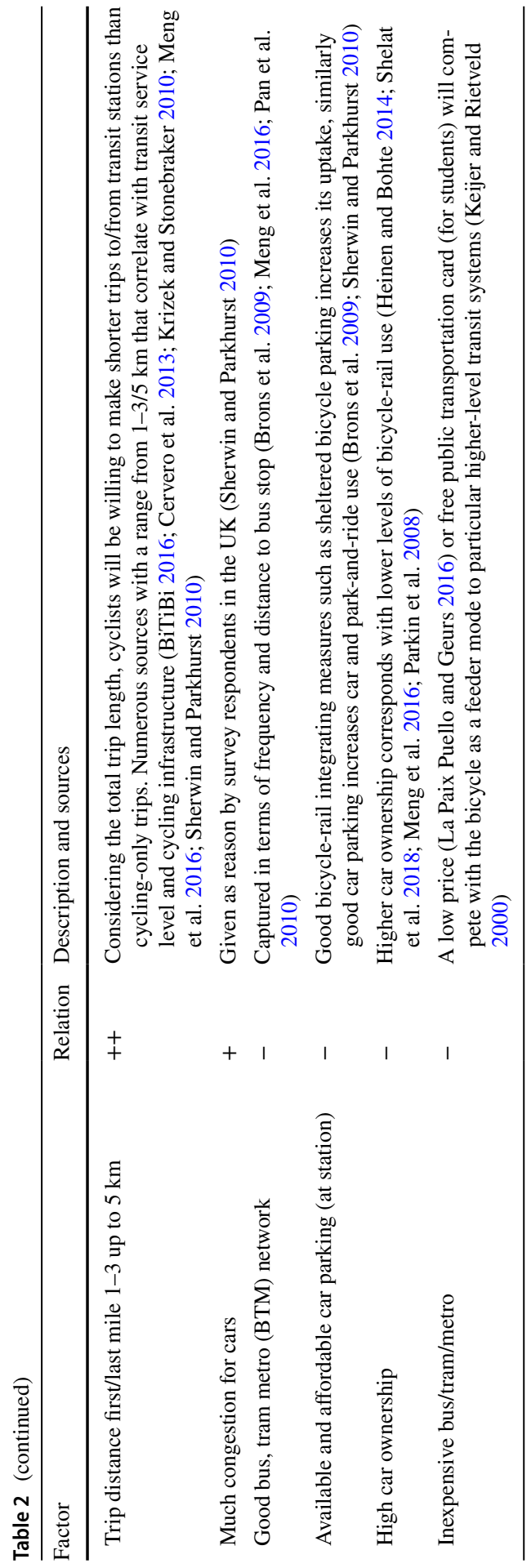




\subsubsection{Bicycle Journey}

The bicycle journey to or from a train station shares many characteristics with other bicycle journeys: an attractive and safe bicycle route will also be attractive and safe for bicycle-transit users. A Dutch study considers the bicycle journey to railway stations in particular. Scheltema (2012) formulated the "bicycle-rail traveller's pyramid of needs". The fundamental conditions of any bicycle(-rail) route are safety and directness including elements like lighting along the route and right of way. The extra value comes from comfort and attractiveness, where elements as liveliness and bicycle parking are included. The importance of directness becomes clear when considering that railway passengers attach much value to reliability (Brons and Rietveld 2009). The cyclist has a train to catch and wishes to have as few traffic lights as possible.

Good cycling infrastructure in quality and quantity has been mentioned in a number of cycle-rail studies to greatly affect bicycle-rail usage. Research in the San Francisco Bay Area, US (Cervero et al. 2013) mentions how "[a number of infrastructure changes] clearly benefited rail stations (...) in attracting cyclists". Bicycle infrastructure was ranked among the top-3 most influential factors in the study by (Krizek and Stonebraker 2010).

\subsubsection{Competition with other modes}

Bicycle-transit can be a faster, cheaper, more comfortable or convenient alternative to other transport mode options. Public transport services and systems vary in the world from minivans to metro, BRT and high-speed rail. Railway services can typically be classified among the higher-service level forms of public transport. The previous section showed that (more) people are willing to cycle (further) to more direct transit services. Therefore, this section will mainly include studies that look into bicycle-rail trips.

A main indicator for mode choice is trip distance. The exact distance that people are willing to cycle can vary, depending on aforementioned factors like station type and geographic characteristics as well as individual preferences. Roughly speaking, the bicycle is most popular between 1 and 3, up to $5 \mathrm{~km}$ distance. Note that travel time and the attractiveness (e.g. safety) of a bicycle route can describe a catchment area better as, for example, the study of Cervero et al. (2013) shows. Typically people will cycle further on the home-bound side of the journey (Krygsman et al. 2004; Meng et al. 2016; Shelat et al. 2018). An overall preference for walking over both cycling and bus to a higher-level transit system seems international, up to a distance of $1 \mathrm{~km}$ (Chen et al. 2012; KiM 2015). The financial costs for the alternatives is also a clear indicator of the attractiveness of the alternative modes (La Paix Puello and Geurs 2016).

Clearly, when both the levels of cycling and rail use are high, the absolute number of bicycle-rail users increases (Kuhnimhof et al. 2010; Martens 2007). This logical reasoning is integrated in various bicycle-rail demand modelling studies (Ensor and Slason 2011; Geurs et al. 2016; Krizek and Stonebraker 2010). Note that this study only includes literature where the combined use of bicycle and public transport is 
considered. The factors described are part of the larger, complex system of our daily choices. Thus, additional relations between the factors will exist. One may expect that high car ownership will typically result in lower levels of cycling and transit use on their own, and with high shares of full-time employment in an area, a higher share of commuters is very likely.

For the complete door-to-door journey, the car will generally be the main competitor. Car ownership among bicycle-rail commuters is slightly lower according to various studies (Heinen and Bohte 2014; Meng et al. 2016), as among cyclists in general (Parkin et al. 2008). Nevertheless, bicycle-rail users often still own a car (Shelat et al. 2018; Sherwin and Parkhurst 2010), just like other rail users (Givoni and Rietveld 2007), indicating they are not 'captive' public transport users per se.

To complete this section on competing modes, the study of Singleton and Clifton (2014) in the US is of interest. The researchers challenged the concept that cycling is a competitor for transit services. On particularly shorter journeys, the bicycle is likely to replace lower-level and lower-frequency public transport services such as bus rides. Meanwhile, as a sustainable long-term alternative to the car, the competition can become a synergy. Whenever a tire is flat or the rain is pouring one can opt for the bus and when the trains are striking the bike is a reliable mode of transport. Their research indicates that transit are short-term mode substitutes, but might be long-term complements. Increases in urban area bicycle commuting were positively associated with transit ridership. More research in this field is recommended by them.

\subsection{Context factors}

Before we zoom into individuals' travel purposes of the stated choice model in the next section, we give the larger context of a cycling culture and attitude towards cycling and typical user-characteristics. How is bicycle and rail use perceived? What characteristics do bicycle-rail-users share? How do transportation alternatives affect the share of bicycle-rail? What transport policy is in place? Answers to these questions will vary depending on where and to whom they are asked. Note that these factors are often more qualitative, making it harder to assign a direct relation. Table 3 shows these factors, their relationship and main sources.

High levels of rail use and bicycle use are not mentioned as factors explicitly in this overview but are assumed to be captured by a 'positive attitude towards rail' and a 'positive attitude towards cycling'.

\subsubsection{Culture and attitude towards transport modes}

The culture around, perceptions of and attitude towards various modes of transport, are all contextual factors which influence a traveller's choice. Particularly the perception of cycling seems to differ per country or social group. 


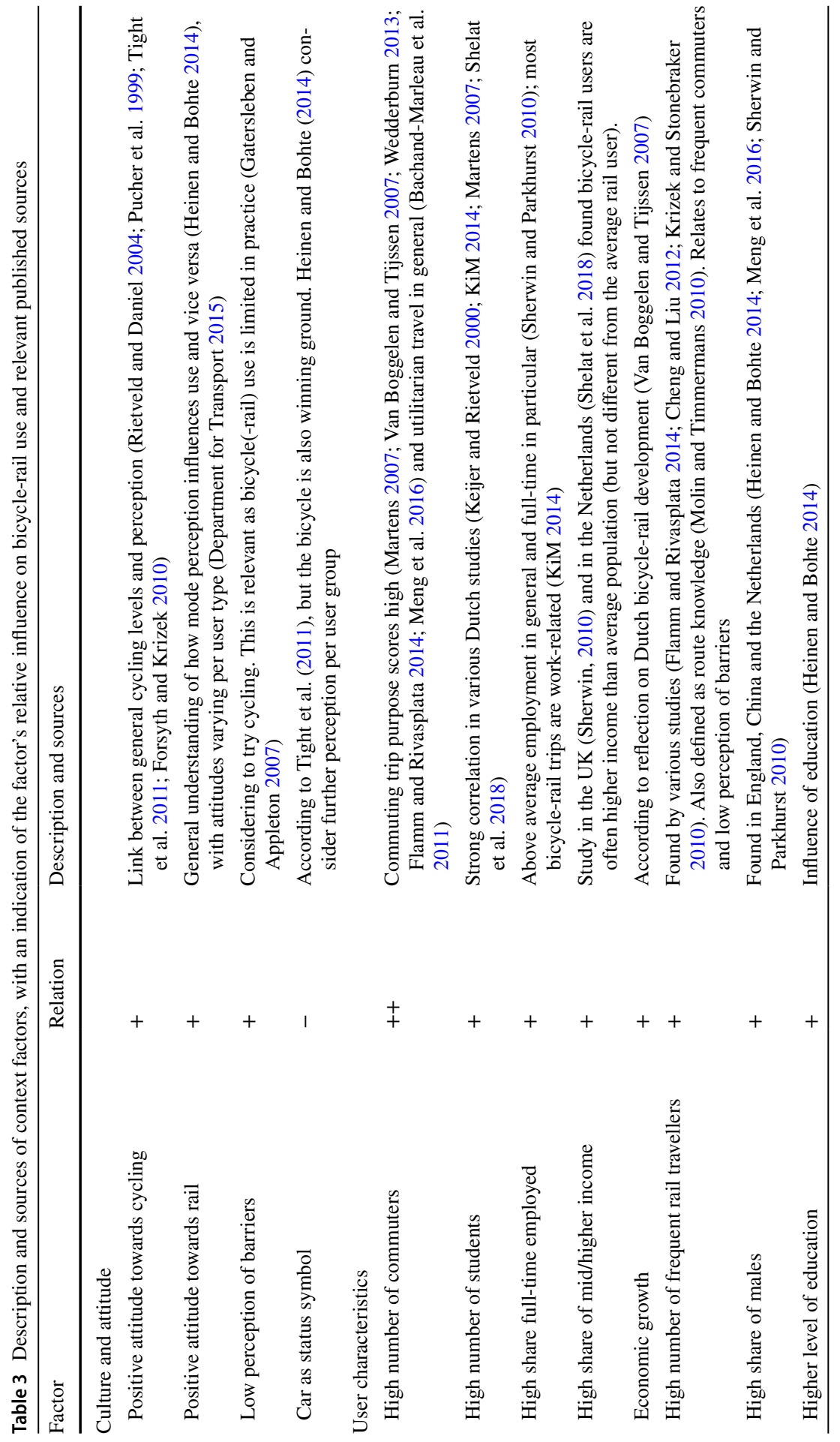




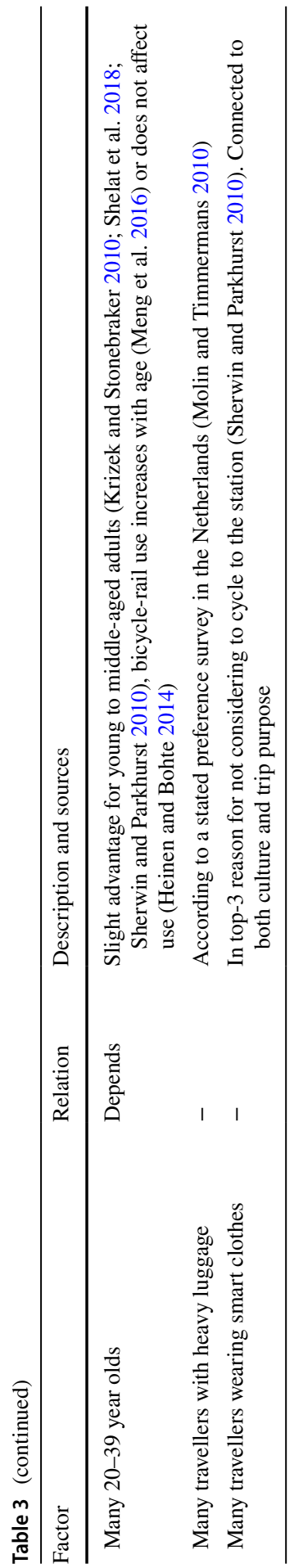


Part of the perception is an interpretation of the actual number and type of cyclists or transit users. If only affluent white males can be spotted cycling on expensive road bikes (dubbed Mamil in some places: a middle-aged man in lycra) or contrarily, only students are going around on cheap and rusty bicycles, cycling will be perceived accordingly (Aldred and Jungnickel 2014). The same counts for expensive train travel that only affluent people can afford or vice versa, where the train (or bicycle) is a poor man's mode of transport for those who cannot afford a car. Negative or stereotypical perceptions can become a barrier to changing people's travelling habits. The phrase 'cycling for all ages and abilities' used by various procycling groups, indicates work is being done on changing perception and hopefully practice.

\subsubsection{Bicycle-transit user characteristics}

Traffic flows are the sum of travel choices made by individuals. Research on who are travelling by bicycle, by transit and even by bicycle-transit has accumulated over the years. The literature review focuses on factors for the combination of the two modes only.

Particularly in this group of factors, large differences between places were found. Where some local studies indicated that income or gender may highly correlate with bicycle(-rail), in other locations these appeared to be insignificant. This should be kept in mind when studying these factors. There remains much work to be done in this field.

Mostly socio-economic factors have been identified in the literature. The differentiation of users lays in age, gender and household size, as well as many travel or occupational themes including trip purpose, education levels, employment rate or types and income but also riding frequencies, route knowledge and even clothing. There are clearly correlations between these factors which are outside the scope of this literature review.

\subsection{Reflection on factors from literature review}

The relatively most influential factors determining the demand of bicycle-transit use emerging from this review are the first/last-mile-distance (most people will cycle up to five $\mathrm{km}$ ), current bicycle and rail use, competition of other modes, safe and highquality bicycle routes to the station, the share of commuters among railway passengers and number of rainy days. The positive feedback loops (and potentially negative loops) between all the stated factors should be studied in more detail to develop our understanding further. These feedback loops are, however, evident: good bicycle infrastructure will increase cycling levels and in turn high cycling levels will push cycling measures on the agenda (e.g. safer cycling routes) which might increase demand for bicycle trains even further, and so forth.

On a system-wide level, good public transportation and high-quality cycling infrastructure can provide a reliable and flexible alternative to the car. People are then less reliant on their car. On an individual's trip choice level, however, there is 
a competition for the first and last mile between the bicycle and its alternatives to reach or leave a railway station. Then, for bicycle-rail in particular, bus, tram and metro systems will work as a competitor.

As bicycle-rail literature is limited and considering these large variations, more than a generic overview cannot be given. It may be assumed that a combination of the factors can give a first indication of the potential for bicycle-rail use.

\section{Results from the stated choice experiment}

An explorative stated choice experiment was set up to find the weights of some factors influencing the bicycle-train mode. Five factors were included in this study. Furthermore, only the access trip was considered and no other modes were included. The five factors are based on mini-interviews with experts and users.

The five factors are:

- Bicycle time: the amount of time it takes to cycle from home to the station.

- Time to park: the time it takes to park your bicycle and walk to the platform.

- Parking costs: the costs of parking your bicycle

- Train time: the time the train journey takes from the chosen station to the destination station

- Transfer: whether there is a transfer within the train trip

\subsection{Choice experiment methodology}

To reveal the relative weights between the five factors a stated preference choice experiment was set up.

In the experiment respondents had to make choices between alternative railway stations which differed in the five factors chosen (see Fig. 2). The experiment per respondent consisted of nine separate choices between two alternatives in an online questionnaire. To design these choices, a pilot study was executed. This information was used to generate a choice set as a D-efficient design, which optimises the information that is generated with a minimal number of choices. This way, the survey did not cost more than $10 \mathrm{~min}$ to fill in. The respondents observe a two or three level choice per factor (parking costs is $€ 0,-, € 0,50$ or $€ 1,00$, train time is 25,35 or $45 \mathrm{~min}$, bicycle time is 5,10 or $15 \mathrm{~min}$ and time to park is 1,3 , or $5 \mathrm{~min}$ ). Transfer was presented as a binary choice.

Statistical analysis was then used to derive the impact of factors on the attractiveness of a station. A multinomial logit (MNL) model was used because it is a fast and efficient way to calculate the parameters, which was in line with the available time for the experiment. The stated choice experiment was incorporated in a questionnaire that was filled out by 269 respondents. Social media targeting resulted in the majority $(>90 \%)$ of the responses and the additional came from travellers who received a flyer at two train stations in Amsterdam ('Amsterdam RAI' and 'Amsterdam Zuid'). The questionnaire also included questions about personal and socio-economic characteristics 


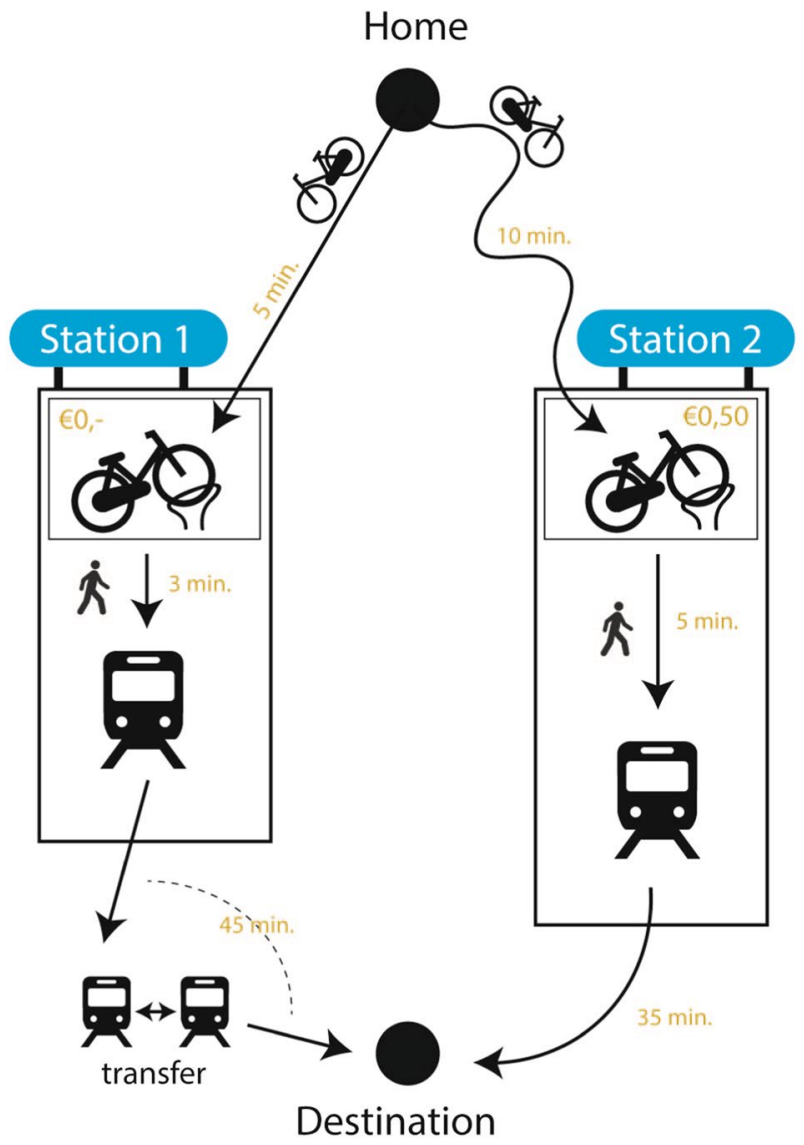

Fig. 2 Example of a choice between two alternatives in the experiment

enabling deeper analysis in those characteristics. More details are available in Van Mil (2017).

\subsection{Results}

\subsubsection{Relative utility of five station-choice factors}

The outcomes are the impact of the five researched factors on the attractiveness (utility) of the bicycle-train mode. The utility was calculated by the following equation. The modelling results are shown in Table 4.

$$
\begin{aligned}
U_{i}= & \beta_{1} \times \text { bicycle_time }+\beta_{2} \times \text { price }+\beta_{3} \times \text { train_time } \\
& +\beta_{4} \times \text { transfer }+\beta_{5} \times \text { time_to_park }+\varepsilon_{1} .
\end{aligned}
$$

By normalising the outcomes ( $\beta$ in Table 4 ), the factors (in utility) can be benchmarked to 'daily used' units like euro and minute. The result of this normalisation is 
Table 4 Outcomes, impact on station attractiveness per factor

\begin{tabular}{lllll}
\hline Factor name & $\beta$ (impact on utility) & SE & $t$ test & $\mathrm{p}$ value \\
\hline Bicycle time & -0.19 & 0.0091 & -21.02 & 0.00 \\
Price & -1.77 & 0.0965 & -18.33 & 0.00 \\
Train time & -0.14 & 0.0061 & -23.28 & 0.00 \\
Transfer & -1.06 & 0.0669 & -15.80 & 0.00 \\
Time to park & -0.13 & 0.0155 & -8.66 & 0.00 \\
\hline Model statistics & & & Value \\
\hline Number of estimated parameters & & 5 & 2420 \\
Number of observations & & & 269 \\
Number of individuals & & & -1677.416 \\
Null log likelihood & & & -1675.005 \\
Cte log likelihood & & & -1677.416 \\
Init log likelihood & & & -1282.648 \\
Final log likelihood & & & 789.536 \\
Likelihood ratio test & & & 0.235 \\
Rho-square & & & 0.232 \\
Adjusted rho-square & & & $+1.061 \mathrm{e}-002$ \\
Final gradient norm & & &
\end{tabular}

visualised in two pentagons, where bicycle time (Fig. 3) and parking price (Fig. 4) are set as a base. For Fig. 3 this means that bicycle time is equal to $1 \mathrm{~min}$. It is possible to create five different pentagons, each with a different base factor. Two of them are shown in this paper. The others can be found in Van Mil (2017). Figure 3 shows that one train transfer in the combined bicycle-train trip is equal to a disutility of almost 6 min bicycle time to the station. This supports anecdotal evidence that people cycle to a railway station further away from their point of origin in order to catch a train which takes them directly to their destination without a transfer. This insight can be used to make certain stations more attractive by tuning the price parameter. MNL modelling showed that consumers are willing to pay $€ 0.11$ for a minute less bicycle time, $€ 0.08$ for a minute less train time, $€ 0.11$ for a minute of less time to park and $€ 0.60$ per avoided transfer.

Bicycle time as a base

See Fig. 3

One minute of bicycle time is equal to $€ 0.11$ (of parking price)

One minute of bicycle time is equal to $1.43 \mathrm{~min}$ of time to park

One minute of bicycle time is equal to $1.36 \mathrm{~min}$ of train time

One minute of bicycle time is equal to 0.18 transfer

Parking price as a base

See Fig. 4

One euro of parking price is equal to $13.2 \mathrm{~min}$ of time to park

One euro of parking price is equal $12.6 \mathrm{~min}$ of train time

One euro of parking price is equal to 1.66 transfer

One euro of parking price is equal to 9.21 of bicycle time 


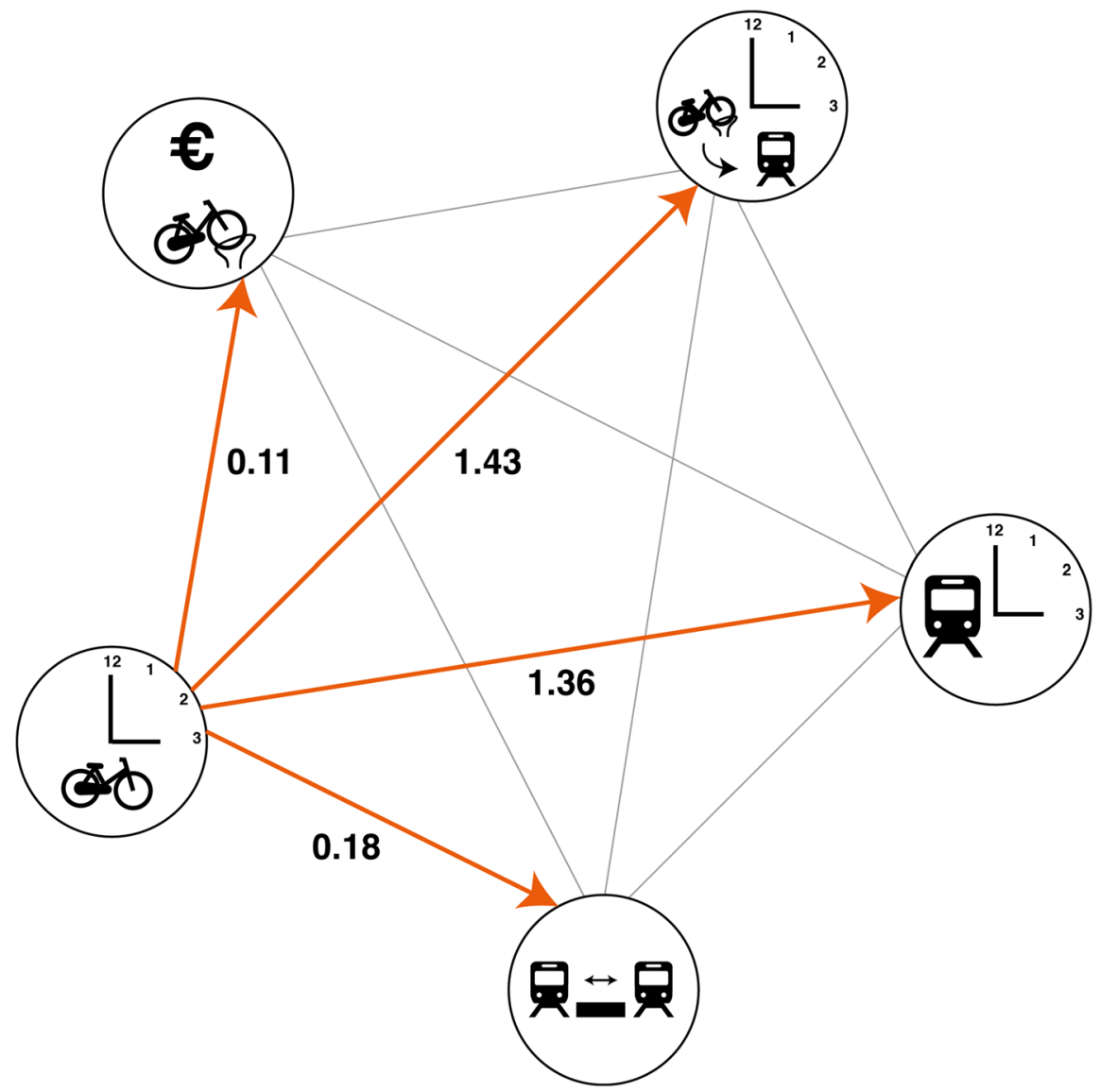

Fig. 3 Interrelation pentagon bicycle time base

\subsubsection{Accounting for student preferences}

Since the choice behaviour in this particular case might differ from one respondent group to another, we briefly analysed the data for one selected group: students. We choose this particular subset of respondents because student behaviour and bicycle parking policies at railway stations are currently highly policy-relevant. Dutch students have a free public transport subscription (with some limitations) implying that around $20-25 \%$ of all train trips during morning and evening peak are made by them (CBS 2016). Additionally, students often use their bike as the access and egress mode to go to campus. This means that especially this group of respondents causes huge pressure on cycling facilities around railway stations in university cities in The Netherlands such as Leiden and Delft. We included the student/non-student personal characteristic as an interaction variable in our MNL model. The results showed that students—not unexpectedly—have a statistically significant higher dislike for 


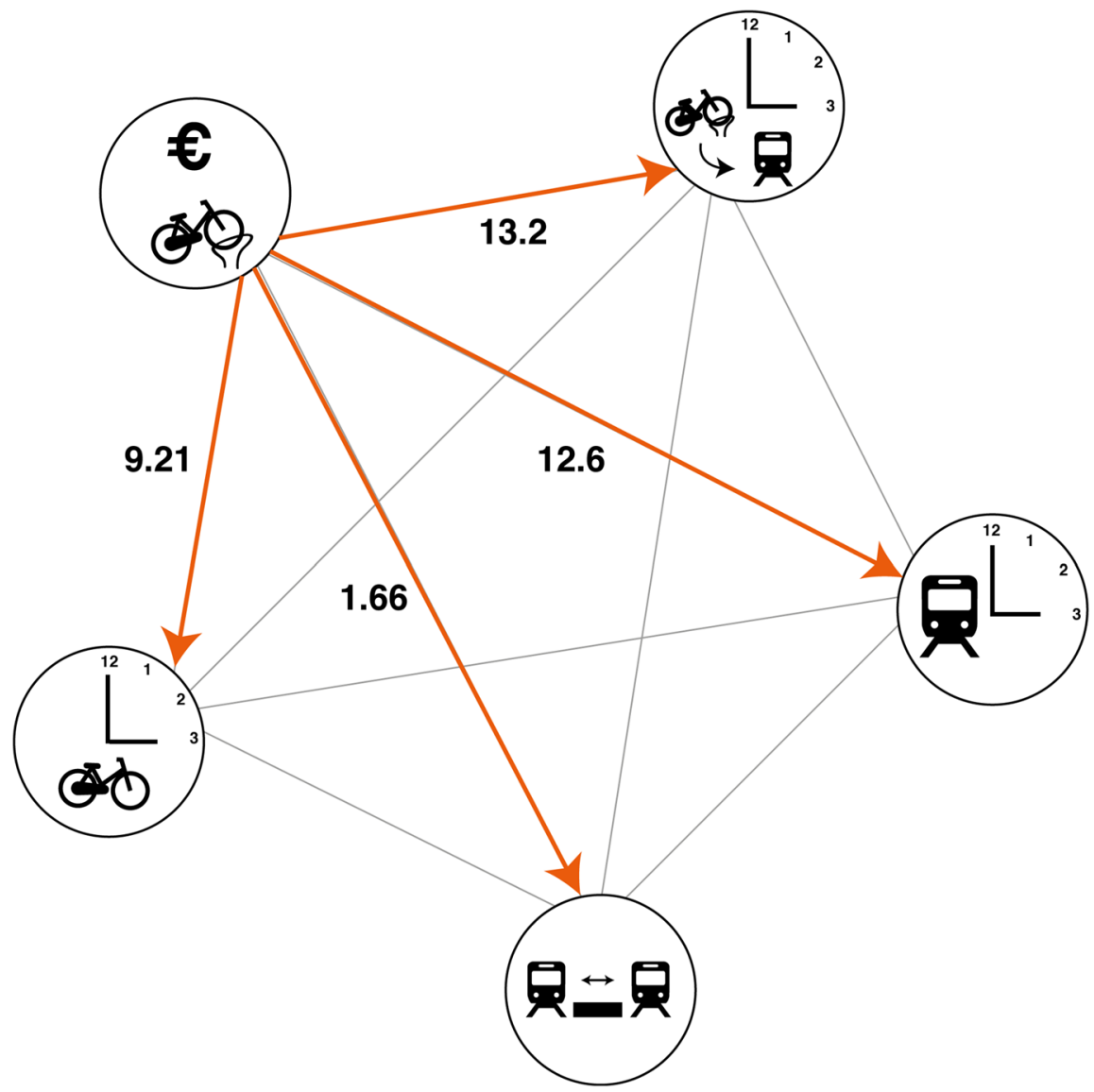

Fig. 4 Interrelation pentagon parking price base

cycling parking costs $(\beta-2.28)$ compared to non-students $(\beta-1.58)$ in their utility function for bike parking. For policy-making this could imply that it might be highly effective to impose a small bicycle parking tariff at railway stations which are completely clogged with student bikes and to make bicycle parking facilities at other near-by stations (but perhaps a bit further away from campus than the one which is clogged) free for them.

\subsubsection{Discussion on generalisability}

The sample used for the choice model (Table 4; Figs. 3, 4) might not be completely representative for the whole population of (potential) bicycle-rail users in the Netherlands. In this section we will discuss the differences and their impacts on the findings. The composition of the respondents in our experiment is shown in Table 5. 
Table 5 Characteristics of respondents

\begin{tabular}{llr}
\hline Personal characteristic & Variable & $\begin{array}{l}\text { Percentage of } \\
\text { respondents }(\%)\end{array}$ \\
\hline Gender & Male & 56 \\
& Female & 44 \\
Age & Under 15 & 0 \\
& $16-24$ & 25 \\
& $25-44$ & 57 \\
Employment & $35-65$ & 17 \\
& Over 65 & 1 \\
& Employed $(>24$ h per week $)$ & 64 \\
& Employed $(<25$ h per week $)$ & 7 \\
Education & Student & 26 \\
& Other & 3 \\
& High & 77 \\
\hline
\end{tabular}

The age of the respondents is compared to the age of users of the Dutch Railways (Van Hagen and Exel 2014). This comparison shows that the age distribution of the choice experiment respondents differs from the distribution of train users. The age categories 16-24 and 25-44 are overrepresented in our experiment while the other categories are underrepresented. Since the outcomes differed between the age categories 25-44 and 44-65, this might have resulted in an underestimation of the general value of time. At the same time, also the youngest category is underrepresented which might compensate for this effect. This, however, cannot be verified, because the outcomes for the other age categories were insignificant.

There is another factor that might have influenced the representativeness of our sample and that is that about $80 \%$ of the respondents are highly educated. Research has been done on typical Dutch bicycle-transit users. This research indicates that users are in general highly educated (Shelat et al. 2018). The overrepresentation of higher educated people in our sample, therefore, might not be too harmful for making our sample not representative for the whole population, but we cannot underpin this clearly, because quantitative underpinning is impossible due to a lack of data about the population. Also, the level of income in our sample might lead to a skewed result. Accurate information about the income of train travellers is not available; therefore, a detailed comparison cannot be made. It could have resulted in an overestimation of the overall value of time, since people with higher incomes are willing to spend more on time savings.

The geographical location of our respondents could have been also of influence on the generalisability for the whole of the Netherlands. Most respondents in this study live in the Randstad area, the Netherlands' most populated region. 


\subsubsection{Validation}

The outcomes were validated by expert interviews and by a comparison with previous research on the value of time. A total of nine experts was interviewed, both researchers and policymakers. In the interviews the focus was on the credibility of the outcomes. They judged the values of time from this research as low. A reason for this could be that in the choice experiment the mode choice was already given to the respondents. Therefore, travellers are already willing to use this mode. The lack of competition with another mode leads to a lower value of time. Most interviewees indicated to be surprised that 'time to park' has a lower weight than bicycle time and an approximately equal weight as in vehicle train time. This is remarkable, because 'time to park' is perhaps one of the most chaotic parts of the trip. Furthermore, it is a transfer which is (based on anecdotal evidence) generally valued very negative. An explanation for this could be that parking is per definition a part of a cycling trip. A part of the negative impact could, therefore, already be in the valuation of bicycle time. The other weights were considered plausible by the experts.

Next to the interviews the components were compared to literature about value of time and time factors. There is not a singular value of time in the literature since it is very context-specific. For travelling, one hour is valued from about $€ 5$ (Antoniou et al. 2007) to about $€ 20$, with a Dutch average of $€ 9.25$ (Warffemius et al. 2016). The value of time calculated in this study ranges from about $€ 4.80$ to $€ 6.60$. This is, despite that it is on the lower boundary, still within the range that can be found in the literature. The calculated transfer penalty $(7.5 \mathrm{~min})$ is within the realistic range of 5-15 min (Warffemius et al. 2016).

\subsubsection{Limitations}

There are limitations to the design of the study: the limited number of included factors and the number and composition of respondents. The method of stated choice acquires outcomes within a non-existing context; when the outcomes are used in a real situation, this should be considered. Furthermore, it was impossible to include all factors that influence station choice. However, the most influential factors were a part of this study. A larger research with a deeper analysis on the factors that influence station choice would have made it possible to include more factors in the study and thereby generate more information. Nevertheless, the number of respondents and observations was high and led to many significant values. The last limitation is that the composition of respondents was not perfect, as discussed in 'generalisability'. Finally, no analysis was executed to account for the panel nature of the dataset.

\section{Conclusions}

This paper shows that many different factors influence the choice for using the bicycle-train combination. An in-depth literature review resulted in six unique transit-related factors, twenty-first-last mile actors and fifteen context-related factors. All these factors might influence the demand for this 'new' mode positively 
or negatively. Some of the factors found in the literature can be influenced by policy-makers and/or operators of public transport (e.g. housing projects near stations, transfers on routes or factors related to cycling infrastructure). Some of the factors are very context-dependent and are much harder to influence (e.g., weather, hilliness, employment, demography), implying that stimulating the demand for the bicycle-transit combination needs also to be context-dependent. The review implies that a one-size-fits-all-policy and project strategy for stimulating the bicycle-transit combination does not exist. We argue that the factors identified in the review can result in positive and negative feedback loops which were not scrutinised in this study. Factors alone can never capture the complexity. Therefore, we recommend further scientific research by identifying these potential feedback loops by using system dynamics, for example.

An exploratory choice modelling study showed that Dutch bicycle-train combination users in our sample are willing to pay $€ 0.11$ for a minute less bicycle time, $€ 0.08$ for a minute less train time, $€ 0.11$ for a minute of less time to park and $€ 0.60$ per avoided transfer. These kinds of insights might give the bicycle and transit sector valuable information to be used in modelling multimodality and cost-benefit analyses, thereby supporting improved decision making and integrated design of bicycle and transit networks. Our choice experiment study had some limitations. Our results are not usable in all bicycle-transit contexts but we think that this way of modelling can result in helpful quantitative information to be used by policy-makers. So, if cities or regions aim to stimulate this 'new' mode, we recommend to carry out these kinds of choice experiments using factors which might influence the utility of the bicycle train combination which are specific for this region or city.

Acknowledgements This research is performed in cooperation with the Dutch Ministry of Transport, engineering consultants Witteveen + Bos and Delft University of Technology. The authors are grateful for their support.

Open Access This article is licensed under a Creative Commons Attribution 4.0 International License, which permits use, sharing, adaptation, distribution and reproduction in any medium or format, as long as you give appropriate credit to the original author(s) and the source, provide a link to the Creative Commons licence, and indicate if changes were made. The images or other third party material in this article are included in the article's Creative Commons licence, unless indicated otherwise in a credit line to the material. If material is not included in the article's Creative Commons licence and your intended use is not permitted by statutory regulation or exceeds the permitted use, you will need to obtain permission directly from the copyright holder. To view a copy of this licence, visit http://creativecommons.org/licen ses/by/4.0/.

\section{References}

Aldred R, Jungnickel K (2014) Why culture matters for transport policy: the case of cycling in the UK. J Transp Geogr 34:78-87. https://doi.org/10.1016/j.jtrangeo.2013.11.004

Antoniou C, Matsoukis E, Roussi P (2007) A methodology for the estimation of value-oftime using state-of-the-art econometric models. J Public Transp 10(3):1-19. https://doi. org/10.5038/2375-0901.10.3.1

Bachand-Marleau J, Larsen J, El-Geneidy A (2011) Much-anticipated marriage of cycling and transit. Transp Res Rec J Transp Res Board 2247:109-117. https://doi.org/10.3141/2247-13 
BiTiBi (2014) Guidelines to implement BiTiBi services. Retrieved from http://www.bitibi.eu/dox/BiTiBi_ guidelines_2014.pdf

BiTiBi (2016) Faster. Easier. Cooler. Evaluation report summary: the pilot projects step by step. Retrieved from http://www.bitibi.eu/dox/BiTiBi_Evaluation Report_Final_January_2017.pdf

BiTiBi (2017) BiTiBi the final report. Retrieved from http://www.bitibi.eu/dox/BitiBi_Final \%20Report_2017.pdf

Blainey S (2010) Trip end models of local rail demand in England and Wales. J Transp Geogr 18(1):153165. https://doi.org/10.1016/j.jtrangeo.2008.11.002

Brand J, Hoogendoorn S, van Oort N, Schalkwijk B (2017) Modelling multimodal transit networks integration of bus networks with walking and cycling. In: 2017 5th IEEE international conference on models and technologies for intelligent transportation systems (MT-ITS). IEEE, pp 750-755. https://doi.org/10.1109/mtits.2017.8005612

Brons M, Rietveld P (2009) Improving the quality of the door-to-door rail journey: a customer-oriented approach. Built Environ 35(1):122-135. https://doi.org/10.2148/benv.35.1.122

Brons M, Givoni M, Rietveld P (2009) Access to railway stations and its potential in increasing rail use. Transp Res Part A Policy Pract 43(2):136-149. https://doi.org/10.1016/j.tra.2008.08.002

CBS (2016) https://www.cbs.nl/nl-nl/nieuws/2016/37/studenten-en-scholieren-pieken-in-de-ochtendspits. Retrieved Mar 2020

Cervero R, Caldwell B, Cuellar J (2013) Bike-and-ride: build it and they will come. J Public Transp 16(4):83-105. https://doi.org/10.5038/2375-0901.16.4.5

Chen L, Pel AJ, Chen X, Sparing D, Hansen IA (2012) Determinants of bicycle transfer demand at metro stations. Transp Res Rec J Transp Res Board 2276:131-137. https://doi.org/10.3141/2276-16

Cheng Y-H, Liu K-C (2012) Evaluating bicycle-transit users' perceptions of intermodal inconvenience. Transp Res Part A Policy Pract 46(10):1690-1706. https://doi.org/10.1016/j.tra.2012.10.013

Department for Transport (2015) Public attitudes towards train services: results from the February 2015 Opinions Survey. Retrieved from https://www.gov.uk/government/uploads/system/uploads/attac hment_data/file/9297/rail-report-2012.pdf

Ensor M, Slason J (2011) Forecasting the benefits from integrating cycling and public transport. IPENZ transportation group conference, Christchurch, New Zealand

Flamm B, Rivasplata C (2014) Perceptions of bicycle-friendly policy impacts on accessibility to transit services: the first and last mile bridge, 100. Retrieved from http://transweb.sjsu.edu/PDFs/research/1104bicycle-policy-transit-accessibility-first-last-mile.pdf

Forsyth A, Krizek KJ (2010) Promoting walking and bicycling: assessing the evidence to assist planners. Built Environ 6(4):429-446. https://doi.org/10.2148/benv.36.4.429

Gatersleben B, Appleton KM (2007) Contemplating cycling to work: attitudes and perceptions in different stages of change. Transp Res Part A Policy Pract 41(4):302-312. https://doi.org/10.1016/j. tra.2006.09.002

Geurs K, La Paix L, Van Weperen S (2016) A multi-modal network approach to model public transport accessibility impacts of bicycle-train integration policies. Eur Transp Res Rev 8(4):25. https://doi. org/10.1007/s12544-016-0212-x

Givoni M, Rietveld P (2007) The access journey to the railway station and its role in passengers' satisfaction with rail travel. Transp Policy 14(5):357-365. https://doi.org/10.1016/j.tranpol.2007.04.004

Groenendijk L, Rezaei J, Correia G (2018) Incorporating the travellers' experience value in assessing the quality of transit nodes: a Rotterdam case study. Case Stud Transp Policy 6(4):564-576. https://doi. org/10.1016/j.cstp.2018.07.007

Harms L, Bertolini L, te Brömmelstroet M (2014) Performance of municipal cycling policies in mediumsized cities in the Netherlands since 2000. Transp Rev 36(1):134-162. https://doi.org/10.1080/01441 647.2015 .1059380

Heinen E, Bohte W (2014) Multimodal commuting to work by public transport and bicycle: attitudes toward mode choice. Transp Res Rec J Transp Res Board 2468:111-122. https://doi.org/10.3141/2468-13

Jonkeren O, Kager R, Harms L (2019) The bicycle-train travellers in the Netherlands: personal profiles and travel choices. Transportation. https://doi.org/10.1007/s11116-019-10061-3

Kager R, Bertolini L, Te Brömmelstroet M (2016) Characterisation of and reflections on the synergy of bicycles and public transport. Transp Res Part A Policy Pract 85:208-219. https://doi.org/10.1016/j. tra.2016.01.015

Keijer MJN, Rietveld P (2000) How do people get to the railway station? The Dutch experience. Transp Plan Technol 23(3):215-235. https://doi.org/10.1080/03081060008717650 
KiM (2014) Mobiliteitsbeeld 2014. Technical report

KiM (2015) Fietsen en lopen: de smeerolie van onze mobiliteit. Technical report

KiM (2016a) Mobiliteitsbeeld 2016. Den Haag. Technical report

KiM (2016b) Toekomstbeelden van het fietsgebruik in vijf essays. Den Haag

KiM (2017) Mobiliteitsbeeld 2017. Technical report

Krabbenborg L (2015) Cycling to a railway station: exploring the influence of the urban environment on travel resistance. MSc thesis, TU Delft

Krizek K, Stonebraker E (2010) Bicycling and transit-a marriage unrealized. Transp Res Rec J Transp Res Board 2144:161-167. https://doi.org/10.3141/2144-18

Krygsman S, Dijst M, Arentze T (2004) Multimodal public transport: an analysis of travel time elements and the interconnectivity ratio. Transp Policy 11(3):265-275. https://doi.org/10.1016/j.tranpol.2003.12.001

Kuhnimhof T, Chlond B, Huang P-C (2010) Multimodal travel choices of bicyclists-multiday data analysis of bicycle use in Germany. Transp Res Rec J Transp Res Board 2190:19-27. https://doi. org/10.3141/2190-03

La Paix Puello L, Geurs K (2016) Integration of unobserved effects in generalised transport access costs of cycling to railway stations. EJTIR Issue 16(2):385-405. https://doi.org/10.18757/ejtir.2016.16.2.3144

Leferink TS (2017) Why cycle to the railway station? MSc thesis. Delft University of Technology

Ma X, Yuan Y, van Oort N, Hoogendoorn SP (2020) Investigating impact of bike-sharing systems on modal shift: a case study in delft, the Netherlands. J Clean Prod 259:120846. https://doi.org/10.1016/j.jclep ro. 2020.120846

Martens K (2004) The bicycle as a feedering mode: experiences from three European countries. Transp Res Part D Transp Environ 9(4):281-294. https://doi.org/10.1016/j.trd.2004.02.005

Martens K (2007) Promoting bike-and-ride: the Dutch experience. Transp Res Part A Policy Pract 41(4):326-338. https://doi.org/10.1016/j.tra.2006.09.010

Meng M, Koh P, Wong Y (2016) Influence of socio-demography and operating streetscape on last-mile mode choice. J Public Transp. https://doi.org/10.5038/2375-0901.19.2.3

Molin E, Timmermans H (2010) Context dependent stated choice experiments: the case of train egress mode choice. J Choice Model 3(3):39-56. https://doi.org/10.1016/S1755-5345(13)70013-7

Pan H, Shen Q, Xue S (2010) Intermodal transfer between bicycles and rail transit in Shanghai, China. Transp Res Rec J Transp Res Board 2144:181-188. https://doi.org/10.3141/2144-20

Parkin J, Wardman M, Page M (2008) Estimation of the determinants of bicycle mode share for the journey to work using census data. Transportation 35(1):93-109. https://doi.org/10.1007/s11116-007-9137-5

Peek G-J, Van Hagen M (2002) Creating synergy in and around stations-three strategies for adding value. Transp Res Record J Transp Res Board 1793:1-6. https://doi.org/10.3141/1793-01

Pucher J, Buehler R (2009) Integrating bicycling and public transport in North America. J Public Transp 12:79-104. https://doi.org/10.5038/2375-0901.12.3.5

Pucher J, Komanoff C, Schimek P (1999) Bicycling renaissance in North America? Recent trends and alternative policies to promote bicycling. Transp Res Part A Policy Pract 33(7):625-654. https://doi. org/10.1016/S0965-8564(99)00010-5

Rail Delivery Group (2016) Cycle-Rail toolkit 2. Technical report, Rail Delivery Group, London, https://www.raildeliverygroup.com/component/arkhive/?task=file.download\&id=469762597

Rietveld P, Daniel V (2004) Determinants of bicycle use: do municipal policies matter? Transp Res Part A Policy Pract 38(7):531-550. https://doi.org/10.1016/j.tra.2004.05.003

Rijsman L, van Oort N, Ton D, Hoogendoorn S, Molin E, Teijl T (2019) Walking and bicycle catchment areas of tram stops: factors and insights. Proc IEEE MT-ITS Conf Krakow. https://doi.org/10.1109/ MTITS.2019.8883361

Scheltema N (2012) Recycle city: strengthening the bike ability from home to the Dutch railway station. MSc thesis, TU Delft

Shelat S, Huisman R, van Oort N (2018) Analysing the trip and user characteristics of the combined bicycle and transit mode. Res Transp Econ 69:68-76. https://doi.org/10.1016/j.retrec.2018.07.017

Sherwin H (2010) Bike-rail integration as one sustainable transport solution to reduce car dependence. University of the West of England. Retrieved from http://eprints.uwe.ac.uk/16859/

Sherwin H, Parkhurst G (2010) The promotion of bicycle access to the rail network as a way of making better use of the existing network and reducing car dependence. European transport conference

Singleton PA, Clifton KJ (2014) Exploring synergy in bicycle and transit use: empirical evidence at two scales. Transp Res Rec J Transp Res Board. https://doi.org/10.3141/2417-10 
Tight M, Timms P, Banister D, Bowmaker J, Copas J, Day A, Watling D et al (2011) Visions for a walking and cycling focussed urban transport system. J Transp Geogr 19:1580-1589. https://doi.org/10.1016/j. jtrangeo.2011.03.011

Van Boggelen O, Tijssen B (2007) Ontwikkelingen van het fietgebruik in voor-en natransport van de trein. Rotterdam

Van der Loop JTA (1997) Intermodality: successes by integrating public transport modes and cycling, pp 21-28. Retrieved from http://trid.trb.org/view/486447

Van Hagen M, Exel M (2014) De reiziger centraal—De reiziger kiest de weg van de minste weerstand. Spoorbeeld. Spoorbeeld. Retrieved from http://www.spoorbeeld.nl/inspiratie/de-reiziger-centraal

Van Mil J (2017) Influencing station choice of cyclists. MSc thesis. TU Delft. Retrieved from https://repos itory.tudelft.nl/islandora/object/uuid\%3A6a9f95f1-0829-404f-852b-f0c7425b24b5?collection=educa tion

Van Nes R, Hansen I, Constance W (2014) Duurzame Bereikbaarheid Randstad: Potentie multimodaal vervoer in stedelijke regio's. Retrieved from http://dbr.verdus.nl/upload/documents/DBR_Notitie_10_ Potentie_Multimodaal_Vervoer.pdf

Verschuren, M. (2016). An origin-destination based train choice model for new public transport connections to train stations. MSc thesis, TU Delft

Warffemius P, De Bruyn M, Van Hagen M (2016) Een nieuwe kijk op de Value of Time!? Colloquium Vervoersplanologisch Speurwerk. CVS, Zwolle

Wedderburn M (2013) Improving the cost—benefit analysis of integrated PT, walking and cycling December 2013. Retrieved from http://www.nzta.govt.nz/resources/research/reports/537

Publisher's Note Springer Nature remains neutral with regard to jurisdictional claims in published maps and institutional affiliations. 